\title{
OS CUSTOS DO BEM-ESTAR SOCIAL: COMO FECHAR A CONTA NO ORDENAMENTO SOCIOECONÔMICO BRASILEIRO?
}

THE COST OF WELFARESTATE: HOW ARE CLOSE THE COUNT IN BRAZILIAN SOCIOECONOMIC ORDINANCE?

\author{
Gina Vidal Marcílio Pompeu \\ Liliane Gonçalves Matos
}

\section{RESUMO}

Por meio deste artigo, discute-se a adequação dos custos do Welfare State à Lei orçamentária como mecanismo para cumprir a ordem socioeconômica brasileira. Para tanto, apresenta-se as teorias econômicas de intervenção do Estado; delineia-se a ordem socioeconômica e aborda-se a adequação do solidarismo às metas orçamentarias. Conclui-se que desenvolvimento social demanda políticas públicas impositivas, entretanto, deve-se considerar as razões do crescimento econômico. A pesquisa é descritiva-analítica, doutrinária e documental sobre: a) as formas de intervenção do Estado; b) a ordem socioeconômica e; c) respeito à Lei Orçamentária. Já a abordagem, é qualitativa pois analisa o papel do Estado.

PALAVRAS-CHAVE: Teorias econômicas. Ordem Socioeconômica. Custos do Estado Social. 


\section{ABSTRACT}

This article discusses the adequacy of the costs of the Welfare State to the Budget Law as a mechanism to implement the Brazilian socioeconomic order. For that, the economic theories of state intervention are presented; the socioeconomic order is outlined and the adequacy of solidarism to the budget targets is addressed. Concluded that social development demands public tax policies, however, one must consider the reasons for economic growth. The research is descriptive-analytical, doctrinal and documentary on: a) the forms of intervention of the State; b) the socioeconomic order and; c) respect to the Budget Law. The approach is qualitative because the analyze the role of the State.

KEYWORDS: Economic Theories. Socioeconomic Order. Costs of the Welfare State.

\section{INTRODUÇÃO}

O desenvolvimento da humanidade está diretamente ligado à Economia. Desde os nômades até a era pós-industrial, percebe-se o desenvolvimento de aglutinações sociais em torno de locais que apresentem condições propícias à subsistência dos indivíduos. Diz-se, por isso, que Direito e Economia estão um para o outro assim como crescimento econômico está para desenvolvimento humano.

O modo como se dá a proximidade entre economia e capital social, entretanto, não é consenso nas teorias que se destinam a estudar a interação entre Estado e Economia. Se é certo que esse relacionamento deve ser íntimo, divergente é a métrica do grau de interferência do Estado nas políticas econômicas. Tal fato pode ser percebido ao se observar a ideologia apresentada nos modelos econômicos do estado Liberal (ou neoliberal), Social (também chamado de Welfare State) e o Regulador.

Esse conflito se mostra atual quando se observa que a explosão econômica vivida pelo Brasil foi insuficiente para desenvolver o capital humano ${ }^{1}$. Embora a economia brasileira seja a nona economia do mundo em termos de $\mathrm{PIB}^{2}$, no que tange ao crescimento do capital humano o país apresenta disparidades que o coloca na septuagésima primeira posição de investimentos em população. A diferença entre desenvolvimento 
econômico e capital humano demonstra a necessidade adotar medidas para incrementar o capital social. Eis porque o discurso de maior e menor intervenção pode ser revisitado na pós-modernidade.

Na busca por efetivar o Welfare State é preciso, A partir de casos concretos, conhecer a forma como a ação estatal pode impactar o mercado e a sociedade. Saber quais medidas adotar, a curto, médio e longo prazo é essencial para direcionar o tomador de decisão a melhorar os indicadores de capital humano. Impossível é aceitar a permanência dessa disparidade no mundo marcado pela Quarta Revolução Industrial. Não à toa, a erradicação da pobreza é meta do milénio prevista na Agenda 2030 da ONU.

Assim, no ambiente em que as barreiras geográficas foram vencidas, a informação é o pilar do mundo globalizado e as empresas ganham forma transnacional, entender o papel do Estado no equilíbrio dos custos do bem-estar social no ordenamento socioeconômico brasileiro, sem se descuidar de desenvolvimento econômico, é medida que se impõe. Neste contexto, se encontram os problemas a serem estudados, quais sejam: quais as formas de intervenção do Estado na economia? Como se estrutura a organização socioeconômica na Constituição Federal do Brasil de 1988? Como equilibrar os custos do Estado do Bem-Estar Social diante da escassez de recursos dispostos na Lei Orçamentária?

Para tanto, Na primeira seção observam-se os modelos de intervenção econômica do Estado. A segunda seção trata das diretrizes positivadas na Constituição Federal do Brasil de 1988 e indica, por meio de dados do Doing Business de 2018 e da CEPAL, a situação do país no ranking de desenvolvimento econômico e de crescimento do capital humano. Por fim, aborda-se a necessidade de adequar os custos do Estado Social à Lei Orçamentária para que, diante de escassez de recursos, se efetive os direitos previstos na Constituição Federal de 1988.

Para atender ao objetivo geral, a pesquisa é descritiva-analítica e versa sobre: a) as formas de intervenção do Estado na economia; b) a ordem socioeconômica brasileira e; c) necessidade de respeito às metas orçamentárias. Traça-se, quanto à abordagem, a pesquisa qualitativa, ou seja, pesquisa subjetiva sobre a conjectura estatal frente aos índices de capital humano e de desenvolvimento econômico. Por fim, o método é 
bibliográfico-documental embasa a ideia de que os direitos sociais são custos e que só poderão ser implementados caso a ordem econômica seja incentivada e em atenção às regras orçamentárias que regem a atividade pública.

\section{TEORIAS ECONOMICA DE INTERVENÇÃO DO ESTADO}

A presença do Estado na economia é discutida por teorias que defendem maior ou menor participação do ente estatal no setor econômico. Dentre essas teorias, é possível destacar o Estado Liberal, o Social e o Regulador como modelo econômico de intervenção na busca por efetivar os fundamentos da ordem política do Estado-nação. Se, por um lado há quem acredite que o Estado deve ter menor participação possível no setor econômico, por outro, o modelo "welfarista", defende maior intervenção.

Ao se analisar as teorias econômicas, percebe-se que a discussão gravita em torno do papel do Estado desde interventor, ao tomar para si a função de controlar a economia e fornecer crescimento social (mercantilismo), até coordenador e regulador da atividade privada (Estados modernos) $^{3}$. As funções estatais variaram conforme o momento histórico e as necessidades sociais que divergem quanto a maior (Estado Social) ou menor (Estado Liberal) participação do governo no âmbito econômico. Com isso, essas teorias buscam angariar o título de política econômica mais adequada e eficiente para a promoção do bem social.

Para o modelo liberal ${ }^{4}$, base da Revolução Comercial, a liberdade individual, segurança das contratações e o respeito à autonomia privada são essenciais. ${ }^{5}$ A teoria afasta a excessiva atuação estatal por acreditar que tal mecanismo impede o perfeito funcionamento do mercado. ${ }^{6} \mathrm{O}$ liberalismo clássico ${ }^{7}$ fincava-se no "dogma da vontade" e na ideologia individualista da "igualdade de todos perante a lei e a plena liberdade de o sujeito atuar, consoante o seu querer, celebrando suas relações, notadamente os contratos" (HUSPEL, 2016, p. 33). Assim, o Estado liberal tinha como marca das relações privadas o contrato, lei entre as partes.

A ordem econômica assentava-se na interação de interesses privados, livremente manifestados no mercado, na liberação comercial, encarregado 
de "realizar a alocação ótima dos recursos, maximizar a produção e prover a população com emprego" (ANTUNES, 2014, p. 16). Nesta seara, quando os indivíduos agiam em interesse próprio, conduzia-se a coletividade à prosperidade e a superação de obstáculos. Ao demonstrar que os sistemas econômicos poderiam se auto ordenar, movidos pelos seus próprios interesses, retirava-se o Estado do campo da economia.

A teoria liberal prevaleceu até a primeira metade do século XIX, quando as guerras mundiais iniciaram o movimento de amenização da "era da vontade", com a relativização da liberdade e da autonomia privada. ${ }^{8}$ A "crise da teoria contratual" 9 fez surgir a chamada "escola solidarista" ou do "Direito Social", próprio do Welfare State.${ }^{10}$ Diante dessa situação, aproximou-se o Estado das relações privadas antes liberalmente "proibidas". Com isso, o Estado abandonou a figura passiva que observava os acontecimentos para intervir nos negócios jurídicos privados. ${ }^{11}$

Huspel (2016, p. 38) intitulou esse movimento como "a derrocada da era da supremacia da vontade", quando "efetivamente o liberalismo começa a ceder". ${ }^{12}$ Reivindicou-se a superação do isolamento do homem liberal, por intermédio do jurídico-constitucional "voltado para a ordem mais solidária e justa, com distribuição mais equilibrada da "riqueza social” (VIEIRA DE ANDRADE, 2008, p. 59). Assim, a revolução neoclássica estruturou o cenário para o Estado do Bem-Estar (Welfare State) em contraste a teoria econômica clássica. As "chagas” das Grandes Guerras precisavam aviar essa receita para cicatriza-la até onde possível ${ }^{13}$.

Para os teóricos do "solidarismo"14, o Estado deveria limitar a ação privada, orientar os investimentos para cumprir direitos sociais e impedir a formação de crise. Se a liberdade individual e a concorrência econômica não tinham conduzido ao melhor dos mundos, ${ }^{15}$ era preciso ${ }^{16}$ (re)construir o sujeito. Com isso, abandonou-se a imagem do sujeitoproprietário ${ }^{17}$ e abriu-se espaço para considerar a existência de vários sujeitos, independentemente da qualidade de proprietário ${ }^{18}$. Esse modelo, entretanto, entra em crise diante da globalização e do pluralismo jurídico. Percebeu-se que o "solidarismo" não dava conta da complexidade da sociedade contemporânea, já que o aumento da intervenção estatal, como pregado pelo Estado Social, impediria a atuação de empresas transnacionais e iria de encontro ao fenômeno mundial. 
Essa fase de maior complexidade social, amparada pela relativização das barreiras geográficas, internacionalização de costumes e padrões de produção permitiu a concepção de novos modelos para atuação do Estado na economia. Propagou-se a ideia de que os recursos são escassos, com isto, era preciso que o Estado atuasse com cautela e eficiência para não desequilibrar erroneamente a economia e desperdiçar os recursos. Assim, ao invés de prestar diretamente serviços públicos e executar atividades econômicas, o Estado deveria assumir as funções de planejamento, regulação e fiscalização, sendo chamado agora de "Estado Regulador".

Os governos ocidentais se deslocaram do Estado Positivo - no qual intervinham diretamente, a fim de alcançar metas sociais e econômicas para o Estado Regulador (MAJONE, 1994, p. 97). Essa guinada é percebida com o repasse, a terceiros, de serviços diretos antes desenvolvimentos pela administração pública. Ocorre que embora o Estado tenha abdicado de certos serviços ele ainda controla e influência as atividades, mediante a mistura de regras, regulações e acordos contratuais.

Para controlar os serviços, na visão de Freiberg (2010, p. 10), o ente público se vale de seis ferramentas regulatórias, quais sejam: (1) ferramentas econômicas (tais como estabelecimento de mercados, tributação, quotas ou atribuição de preços); (2) ferramentas transacionais (nas quais os governos influenciam o comportamento através do contrato ou concessão de condições); (3) ferramentas de autorização (tais como registro, licença ou acreditação); (4) ferramentas informacionais (como a rotulagem de produtos ou regimes de divulgação contínua); (5) ferramentas estruturais (de projeto físico, ou processos como nossos arranjos fiscais); e (6) ferramentais legais (tais como leis, normas e regulamentações).

É por isso que se diz que se está na "era da governança regulatória" (MINOGUE, 2002) ou do "capitalismo regulatório" (LEVI-FAUR, 2005) ${ }^{19}$. A crescente confiança no mercado como veículo, tanto para maximização de riquezas individuais quanto para o provimento de serviços governamentais, tem sido acompanhada da proliferação de novas regulações (e regimes regulatórios) para garantir a eficiência e a efetividade do mercado. Além de visar a responsabilidade social das organizações do setor privado, para as quais o governo delegou algumas de suas funções. ${ }^{20}$ 
Para que se compreenda o modelo estatal de intervenção econômica que o Estado-nação adotou é preciso observar as diretrizes constitucionais previstas na ordem socioeconômica brasileira. Para tanto, há que se observar a relação entre Estado e povo retratada no preâmbulo da Constituição do Federal do Brasil de 1988. Só depois disso é possível compreender a diferença existente entre desenvolvimento humano/ crescimento econômico.

\section{A ORDEM SOCIOECONÔMICA BRASILEIRA}

A Constituição da República Federativa do Brasil de 1988 (CF/88), publicada em 5 de outubro de 1988, estabeleceu compromisso com o Welfare State. 0 legislador originário prescreveu capítulos específicos para tratar tanto dos direitos sociais (no capítulo II do título II) quanto da ordem social (título VIII) ${ }^{21}$. De forma a ajustar os fundamentos da República para efetivar diretrizes já vivenciadas por ordenações como a da Itália, de Portugal, da Alemanha, entre outras, a saber:

Assegurar o exercício dos direitos sociais e individuais, a liberdade, a segurança, o bem-estar, o desenvolvimento, a igualdade e a justiça como valores supremos de uma sociedade fraterna, pluralista e sem preconceitos, fundada na harmonia social e comprometida, na ordem interna e internacional, com a solução pacífica das controvérsias (Preâmbulo da Constituição Federal do Brasil de 1988).

Com isso, a Constituição brasileira de 1988 ganhou vieses sociais que lhe garantiram o título de "cidadã". Cumpre lembrar, entretanto, que a CF não esqueceu de estruturar a ordem economica (título VII). Previu, no art. 170, que a ordem econômica seria embasada "na valorização do trabalho humano, na busca do pleno emprego, na existência digna, na justiça social, na redução das desigualdades regionais e sociais, na defesa do meio ambiente" (BRASIL, 1988).

Assim, por intermédio desse título, posicionou o Brasil no rol dos países capitalistas, voltado para a valorização da "livre iniciativa" e da "livre concorrência" 22, mas com sentido social. Diz-se, portanto que, o ordenamento brasileiro, entretanto, não cuidou apenas dos direitos 
sociais. A CF/88 também se preocupou com o aspecto econômico, eis porque é preciso interpretar a ordem econômica e a social de forma harmônica, embora haja elementos que, por vezes, a priori se mostrem até antagônicos, como livre iniciativa e valores sociais do trabalho ${ }^{23}$.

A ausência de correlação direta entre esses princípios é percebida no contraste entre crescimento econômico e o desenvolvimento do capital humano. Historicamente, o processo de formação do Estado brasileiro traz respostas quanto a estrutura do governo e o desenvolvimento socioeconômico. 0 desenvolvimento brasileiro se deu tardio ${ }^{24}$ tanto se comparado com as economias da América do Norte ${ }^{25}$ como dentro da própria América do $\mathrm{Sul}^{26}$, a exemplo do que aconteceu com o Chile e a Argentina ${ }^{27}$.

0 receituário neoliberal também chegou atrasado no Brasil $^{28} \mathrm{o}$ que reafirmou a tensão entre desenvolvimento econômico e efetivação de direitos sociais. A demora brasileira em se lançar no mercado trouxe implicações diretas ao desenvolvimento econômico e ao capital social do país ${ }^{29}$. Em termos de PIB ${ }^{30}$ per capita - ou renda per capita - "o Brasil cresceu 12,7 vezes entre os anos de 1900 e 2000. Embora o crescimento tenha sido expressivo, por ter partido de base muito baixa, foi insuficiente para colocar o país entre as nações de maior poder aquisitivo" (ALVES; BRUNO, 2006, p. 2).

Além disto, "a forma de apropriação da riqueza se deu de maneira desigual, pois a herança escravista e patrimonialista, aliada ao processo de 'cidadania regulada' fez do país um campeão mundial de concentração de renda" (SANTOS, 1979). Neste viés, há que se aperceber que a viabilidade das economias capitalistas não resulta natural e espontaneamente do livre jogo dos "mecanismos de mercado". Instituições, leis, convenções, normas e regras devem assegurar as liberdades individuais de maneira compatível com as necessidades sociais e com as condições de reprodução do conjunto do sistema econômico.

Os benefícios sociais dos mercados livre e concorrenciais não são acessíveis sem a interveniência das instituições nos processos de crescimento econômico e de distribuição dos frutos do progresso social (BRUNO, 2014, p. 12). Essa situação fez com que o legislador originário positivasse os direitos sociais para proteger direitos coletivos. Acreditava- 
se que diante de instituições fortes, tal como o Estado, seria mais fácil assegurar que a busca pelo crescimento econômico não sufocasse direitos sociais essenciais.

Embora não se negue a importância da atuação estatal, é preciso lembrar que a previsão normativa, por si só, não tem o condão de modificar, ou pelo menos diminuir, os entraves históricos do desenvolvimento brasileiro. Putnam (2002, p. 31) lembra da necessidade de formar "cidadãos atuantes e imbuídos de espírito público, por relações políticas igualitárias, por uma estrutura social firmada na confiança e na colaboração". As qualidades apontadas pelo autor são essenciais para o êxito das medidas que se pretende alcançar, pois a relação entre cultura e estrutura implica no entendimento causal entre normas e atitudes culturais.

No mesmo sentido, Ostrom (2011) afirmar que embora os indivíduos sejam regidos por racionalidade limitada ${ }^{31}$, isso não quer dizer que sejam egoístas $^{32}$. Para a autora, o egoísmo adviria da cultura e do ambiente em que ela se encontra. Ostrom reitera o discurso de Putnam sobre a necessidade de formar o patamar mínimo civilizatório. ${ }^{33}$ A partir dessa construção social, que prescinde de normas e sistemas de participação cívica, será possível contribuir "para a prosperidade econômica e são, por sua vez, reforçados por esta prosperidade" (PUTNAM, 2002, p. 190). ${ }^{34}$

As construções sociais, entretanto, deveriam funcionar sob a ótica da governança, ou seja, da auto-organização de comunidades a qual, até certa medida, dispensa, mas não exclui, as intervenções dos atores de mercado e do Estado (OSTROM, 2003). Nesse sentido, a governança, na visão da Escola de Indiana, representada por Ostrom é entendida como a capacidade que as comunidades têm se organizarem, em diferentes locais e momentos, com o objetivo de gerir um bem comum por meio de condições que o torne mais efetivo, eficiente e estável. Essa capacidade organizativa evitaria, assim, a escassez desse bem, para assegurar a sustentabilidade (McGINNINS, 2011).

Dessa forma, os estados-nação e seus governos devem ser vistos como condutores do processo de desenvolvimento na medida em que são instituições necessárias para formar sua nação. Embora imprescindível, o desenvolvimento humano brasileiro não alcança o nível esperado para a plena construção de seus cidadãos. Este fato é observado nos relatórios 
que objetivam ajudar os governos a olhar para setores sociais e/ou econômicos com dificuldades e melhorar seus rendimentos.

No Índice de Desenvolvimento Humano - IDH, por exemplo, que verifica a formação do capital humano, o Brasil ocupa apenas o 79o35 lugar (ONU, 2018) ${ }^{36}$. A situação é mais alarmante quando observado os índices do Anuário da Comissão Econômica para a América Latina CEPAL $^{37}$. Neste anuário, constatou-se taxa de crescimento populacional de 0,8\%; de mortalidade infantil até os 5 anos de 19,5\%; de acesso aos serviços básicos da população situadas na faixa de extrema pobreza de $4,6 \%$ e 16,5\% para aqueles que estão na faixa de pobreza (CEPAL, 2016) ${ }^{38}$.

Vê-se, com isso, que o desenvolvimento do capital humano brasileiro não guarda relação direta com o grau de crescimento econômico que o país apresenta. 0 Brasil é a 9a (nona) maior economia mundial em termos de PIB per capita. A boa colocação do país e suas projeções positivas ${ }^{39}$ também estão dissociadas do ranking do Relatório do Banco Mundial, Doing Business de $2018^{40}$. O relatório que estuda a facilidade de fazer negócios e compara 190 (cento e noventa), posicionou o Brasil está na 109 (centésima nona). Os números mostram que a economia brasileira é forte, mas o ambiente de negócios precisa ser trabalhado.

Como mencionado, a ordem economica e social devem ser alinhadas. De nada adianta ter economica forte se não há confiabilidade nas instituições para realizar transações ou mesmo ter população sem qualidade de vida. Deve-se lembrar que uma das metas do milênio estabelecida pela Agenda 2030 da ONU é a erradicação da pobreza, a redução das desigualdades dentro dos países e entre eles, por meio do trabalho digno e crescimento econômico ${ }^{41}$. Se os Estados signatários, Como o Brasil é, comprometeramse com a meta, então é precisop equacionar a balança desenvolvimento econômico/crescimento do capital humano.

Assim, para a população desses Estados alcançar o patamar mínimo civilizatório, o perfil econômico e o capital humano devem estar de mãos dadas. Esses preceitos não podem ser antagônicos ou se anularem. Mas devem ser complementar. A inclinação da balança para um dos lados desalinha os preceitos constitucionais e tornam as normas dirigentes sem forças para efetivação. Essa relação será analisada a partir da visão de que os custos da implementação do Estado Social devem estar delineados 
para que a população desfrute do verdadeiro Welfare State sem prejuízo de desenvolvimento econômico, fundado na confiança e no bom ambiente de negócios.

\section{A LEI ORÇAMENTÁRIA COMO INSTRUMENTO PARA BALANCEAR OS CUSTOS DO ESTADO SOCIAL}

A adequação entre desenvolvimento econômico e crescimento humano demonstra a importância de se ter instituições fortes, tal como o Estado, capazes de efetivar esse sem prejuízo daquele. Esta perspectiva é defendida por Smith desde "A riqueza das Nações". ${ }^{2}$ Para o autor, "caberia ao Estado defender a sociedade contra a violência e invasão de outras sociedades; proteger seus membros contra indivíduos do mesmo grupo; e, construir e manter obras e instituições públicas, que não interessem a um indivíduo ou a pequeno número" deles (SMITH, 1996, p. 612).

Essa visão demonstra a imprescindibilidade da existência do Estado tanto para o mercado quanto para a sociedade. Nessa medida, a este, o Estado garante que o patamar mínimo civilizatório seja efetivado, aquele o respeito às regras do jogo para maximizar os benefícios dos indivíduos e atuar com maior liberdade ${ }^{43}$. Veja que o contratualista não defendia a ideia de que bastaria a divisão do trabalho e a existência de mecanismos puramente mercantis e concorrenciais para assegurar automática convergência do ótimo econômico com o ótimo social.

A partir dessa visão, Smith lança as bases da própria análise econômica apoiada na atuação estatal como forma de desenvolver os mercados e satisfazer os anseios sociais. Não se pode esquecer que a democracia é, grosso modo, a manifestação individual na formação da vontade geral (lei), e os direitos fundamentais estão fortemente vinculados ao reconhecimento (e respeito) pelo Estado de direitos naturais a ele preexistentes (AQUINO; BUSSINGUER; BELIZÁRIO, 2008, p. 70) ${ }^{44}$, então sua aplicação precisa ser levada a sério. Esta é, segundo a visão de Canotilho (2001), a tarefa que o Estado, que tem Constituição dirigente ${ }^{45}$, deve cumprir ${ }^{4647}$.

Se por um lado o Estado se propõe a ampliar as políticas públicas voltadas para o crescimento do capital humano, por outro é preciso 
analisar como se dará o custeio para não prejudicar desenvolvimento econômico. É preciso equilibrar as duas ordens, pois o Estado não tem a mesma dinâmica que o setor privado. ${ }^{48}$ Essa noção ganha destaque com a publicação de "The cost of rights", de Sustein e Holmes (1999) ${ }^{49}$. Os autores afirmam não existir direitos negativos e direitos positivos, para eles "os direitos sempre seriam positivos, independentemente de sua geração, pois sempre exigiriam do Estado atitude comissiva de proteção e/ou concreção do direito".

Concluem, quase que em proposição silogística, que se os direitos sempre implicam em custo ao erário e a sociedade sempre seria onerada, então os Direitos Fundamentais deviam sempre ser analisados nesta ótica. A análise economica desses direitos estabeleceu novo padrão interpretativo, pois, embora, esses direitos sejam cláusulas pétreas, “a tendência interpretativa gradativamente implantada pelos neoliberais é sempre no sentido da perniciosa reclassificação, deslocando-os do eixo compromissário-social para o eixo patrimonial" (ROSA; MARCELINO, 2009, p. 12). Não se pode efetivar o Welfare State a todo preço, é preciso ajustar os custos ao plano do governo. ${ }^{50}$

0 equacionamento entre o que se pretende fazer e o orçamento que se tem para fazer, é encargo do chefe do Executivo. A este cabe atenção às contas públicas para não incidir em crime de responsabilidade, tal como se deu com a presidente Dilma Rousseff ${ }^{51}$. Os problemas oriundos da falta de atenção à Lei Orçamentária atingem a ordem econômica do país, pois as agências especializadas em classificação de riscos ${ }^{52}$ utilizam, como base para a atribuição de sua nota, a capacidade do governo em economizar recursos para pagar os juros da sua dívida ${ }^{53}$.

Nesse sentido, as Leis orçamentárias aparecem como mecanismo de adequação. "A construção do Estado Democrático de Direito requer que custos e estratégias sejam considerados, uma vez que não há Estado Social sem que haja, paralelamente, Estado Fiscal" (MENDES, 2012, p. 1491). As diretrizes da administração pública devem ser ajustadas às metas orçamentárias, pois os recursos para implementação são escassos. Eis a importância de respeitar a Lei de Diretrizes Orçamentárias (LDO) ${ }^{54}$, elo entre o Plano Plurianual (PP), que delineia as políticas públicas a serem implantadas em quatro anos, e a Lei Orçamentária Anual (LOA), que fixa 
metas $^{55}$ e prioridades do Poder Público e dispõe sobre as alterações na legislação tributária.

Quando o Estado não respeita as Leis orçamentárias e gasta mais do que deveria há desajuste na balança fiscal. 0 desequilíbrio aumenta a dívida externa e obriga o país a pagar juros e contrair empréstimos, mediante a desestruturação da Política Fiscal inicialmente prevista no Plano Plurianual. A retomada do controle fiscal perpassa dois caminhos: reforma fiscal, com corte de benefícios de segmentos organizados da população, ou a continuação do modelo atual com a tentativa de evitar o custo político do ajuste. ${ }^{56}$

Isso implica dizer que se não há produção de riquezas, o Estado é tão somente, arrecadador de receita e administrador dos recursos públicos. Essa função deve ser desempenhada com atenção às metas, pois em caso de desajustes, uma das medidas para reequilibrar o orçamento governamental é o aumento da cobrança de renda. Veja que toda a política fiscal tem como base arrecadar e que, para ampliar o recolhimento, é preciso intervir mais na economia. Nesse intuito, o Estado pode assumir a figura de interventor ou regulador. Defende-se que a figura interventora não seria a mais adequada no mundo pós-moderno.

Controlar o desenvolvimento econômico não é a melhor alternativa no mundo globalizado em que as instituições sociais têm patamares supranacionais. Ademais, os incentivos governamentais devem impulsionar a atividade concorrencial. Ao Estado cabe regular ${ }^{57}$, por meio das agências, o mercado e incentivar o pleno desenvolvimento econômico, a partir da distribuição de "subsídios, incentivos fiscais, proteger o mercado, preços e tarifas especiais de produtos e serviços públicos, além de infraestrutura e investimentos em setores básicos" (GOLDENSTEIN, 1994, p. 44).

Essa regulação é eficiente e auxilia a ordem economica a custear a social. 0 desenvolvimento de negócios traz consigo fatores que são almejados pela comunidade. Entretanto, o pleno desenvolvimento econômico demanda garantia e segurança jurídica. Estabelecer as regras do jogo, com vista a estruturação do mercado, é essencial à consecução do patamar mínimo civilizatório. Eis porque "as leis orçamentárias são indispensáveis para a concretização dos direitos fundamentais. Podem, por isso, ser consideradas como a maneira de efetivar os ditames 
constitucionais e permitir a atuação do administrador público" (MASTRODI; RODRIGUES, 2016, p. 4).

Sem elas, estar-se entregando "cheque em branco" ao Estado para alterar a legislação tributária, inclusive com a previsão de novos impostos, mudanças de alíquotas, entre outros ${ }^{58}$. Tal fato implica que cada direito corresponde a custo financeiro público, pois eles têm dimensão impositiva. Assim, "sejam eles direitos que demandam ação positiva do Estado (saúde e educação), sejam os que impõem abstenção" (POMPEU; AGUIAR, 2016, p. 180) os direitos precisam ser visualizados dentro do orçamento, "para que se controlem os gastos públicos ao se comparar receitas e despesas" (CAVALCANTE; CABRAL, 2014, p. 6).

A efetivação dos direitos encontra barreiras na escassez de recursos e na inevitabilidade de se buscar o superávit das contas públicas ${ }^{59}$. Diante da não abundância, escolhas devem ser feitas para ajustar a disponibilidade financeira e orçamentária e cumprir as diretrizes constitucionais. Dessa forma, "cumpre ao Estado editar normas que respeitem a concorrência leal, e que também possam minimizar os riscos. Já que a empresa é ente econômico de inegável importância social" (POMPEU; MAGALHÃES, 2016, p. 117).

A nova lógica, com a consequente e inevitável subordinação do Direito ao econômico, estabelece que as normas constitucionais que declaram e garantem Direitos Fundamentais passem a ser interpretadas sob a égide da relação custo-benefício (ROSA; MARCELLINO, 2009, p. 12). Com isso, racionaliza-se a econômica como parâmetro de proporcionalidade e razoabilidade na busca do equilíbrio das contas públicas e o alcance da justiça social (GALDINO, 1995, p. 218).

Possibilitar crescimento para só empós garantir que todas as pessoas, independentemente do nível de renda, possam ser beneficiadas é medida que se impõe. Para isto, requer-se ambiente propício para florescer novos aprendizes e boas ideias. 0 Estado não deve intervir na economia desregulamente, é preciso ter parâmetros reguladores de balanceio do crescimento econômico/desenvolvimento do capital humano. Tal postura perpassa por aplicação políticas públicas eficientes, incentivo ao mercado e atenção às Leis Orçamentárias. 
Se por um lado os governos são constantemente convocados a salvaguardar cada vez mais direitos e fornecer proteção contra variedade maior de riscos, por outro eles precisam projetar os encargos fiscais e regulatórios dos contribuintes, dos regulados e da sociedade em geral. 0 equilíbrio eficiente do mercado e das demandas da sociedade por proteção contra os piores excessos desses mercados e a eficiência econômica com justiça, equidade e razoabilidade é medida que se impõe. É preciso, entretanto, deixar claro que a regulação tem duas vertentes: uma economica e uma social ${ }^{60}$.

Embora haja diferença entre os tipos de regulação, não raro, "os governos estão crescentemente usando a regulação para entregar metas sociais tradicionalmente fornecidas através de ação direta do governo e técnicas regulatórias baseadas na economia, para definir e resolver problemas sociais" (WINDHOLZ; HODGE, 2013, p. 20). ${ }^{61}$ Isso possui impactos significativos para os atuais reguladores e para a atividade regulatória. Defende-se aqui que a regulação social deve passar pelo incentivo às empresas economicamente produtivas, pois elas poderão auxiliar no crescimento do capital humano.

Não é difícil perceber que à atividade mercantil está atrelada melhoria de vida, com a consequente geração de empregos e incentivo à economia nacional. Impor "coleiras" ao mercado para que se cumpra funções que não são suas não é o caminho que deve ser seguido. A empresa não deve ser vista como agente das funções estatais, mas meio para se alcançar o fim que se espera, qual seja: atividade economicamente produtiva que, reflexivamente, desenvolve capital humano. A regulação econômica, nessa perspectiva, não deve "controlar", mas fiscalizar a atividade para impedir abusos à ordem econômica.

É preciso deixar que a economia se regule com os parâmetros mínimos dados pelo Estado. Estes serão a base da barganha empresária. Como dito, segurança e previsibilidade são mecanismos essenciais para o desenvolvimento da atividade empresária e, nesse sentido, é algo que o Estado pode, e deve, fornecer. Assim, quando as previsões econômicas falharem o Estado deve garantir que as normas sejam cumpridas, com isso se terá confiabilidade nas instituições. A insegurança das previsões 
econômicas e da força estatal nesses momentos traz externalidades prejudiciais à economia e afastam os investidores.

Em nenhum cenário tal situação deve estar presente, sob pena de se gerar crise econômica e com isso a quebra generalizada da atividade. Acredita-se, por isso, que a empresa é sim capaz de auxiliar o Estado no desenvolvimento do capital humano, na medida em que consegue realizar suas atividades. Para tanto, incentivar, distribuir, ampliar e auxiliar são mecanismos que devem ser usados pelo governo. De modo que a equalização entre desenvolvimento do capital humano e crescimento humano seja realizado, mediante o ajuste às Leis orçamentárias e incentivo às empresas.

\section{CONCLUSÃO}

Quando se analisa a origem da humanidade, há que se perceber que desde sempre a Economia esteve interligada à sobrevivência dos indivíduos. Diante desta situação, surgem teorias econômicas que discutem o grau de intervenção do Estado, sem, contudo, negar a sua importância. Assim, há modelos que defendem maior atuação estatal (Social), que o restringem, basicamente, a funções institucionais e de organização dos poderes (Liberal) e o que acreditam na necessidade de regular a atividade privada (Regulador).

0 último modelo é o que mais se adequa aos preceitos dirigentes da Constituição Federal de 1988, que segue o modelo de outros países, a saber Itália, Portugal e Alemanha, e positiva em seu ordenamento compromissos com o cerne de proteger a dignidade humana, preceito principiológico aberto. Por tal fato, a participação do Estado passa a ser visto como necessária para aplicação dos direitos sociais. De forma que cabe a ele assegurar o cumprimento dos direitos fundamentais e efetivar sua implementação, situação antes deixada ao cabo das relações privadas. Exige-se, assim, postura ativa do governo.

Essa postura, entretanto, deve ser vista com restrições, pois cada direito corresponde a custo e todos os custos estatais devem estar previstos nas Leis Orçamentárias. Não se está a negar a importância dos 
direitos sociais para o desenvolvimento do capital humano, entretanto, irresponsável é perder de vista que o orçamento fiscal é imprescindível. Sem ele estar-se-ia entregando cheque em branco para que o governo implementasse políticas expansionistas, tais como a que desembocou no impeachment da presidente Dilma Rousseff.

A falta de respeito às metas orçamentárias prejudica as notas do grau de investimento do país nas agências especializadas em investimento e, consequentemente, o ambiente de negócios brasileiro. Essa situação é danosa não só para a economia, mas também para o desenvolvimento econômico, pois com baixos índices de confiabilidade os investidores terão medo de aplicar recursos no país. E é certo que a economia precisa de segurança para se desenvolver.

Essa perspectiva, encontra amparo quando se observa que na $\mathrm{CF}$ de 1988, o constituinte originário, não positiva apenas direitos sociais. Também se estabelece como direito fundamental a livre iniciativa e a atividade privada. É bem verdade que o homem ocupa o centro do ordenamento e que a CF, por ser a norma superior, deve banhar os demais textos legais, entretanto, não se pode esquecer que o Estado não produz riquezas. Ele é ente arrecadador que administra os tributos recolhidos.

Neste ínterim, os recursos são escassos e precisam ser estrategicamente pensados para melhor garantir o bem-estar social. É por este motivo que os organismos internacionais se voltaram a produzir relatórios anuais para fornecer dados concretos sobre a realidade dos Estados. Se se sabe que os recursos são escassos é necessário perceber onde aplica-los de modo a promover desenvolvimento socioeconômico.

Apesar de vivenciar acelerado crescimento econômico, até 1950 o Brasil ainda era pobre e agrícola com renda per capita baixa e indicadores sociais precários. 0 crescimento de 12,7 vezes, em termos de PIB, entre os anos de 1900 e 2000, embora expressivo, sem dúvida, parte de base muito baixa. Por isso, esse crescimento foi insuficiente para colocar o país entre as nações de maior desenvolvimento do capital humano.

Tal fato pode ser observado quando se analisam relatórios internacionais. No Índice de Desenvolvimento Humano - IDH, por exemplo, o Brasil ocupa apenas o 79ํ lugar (ONU, 2018). A situação é mais alarmante quando observado os índices do Anuário da CEPAL que constatam taxa 
de crescimento populacional de $0,8 \%$; de mortalidade infantil até os 5 anos de 19,5\%; de acesso aos serviços básicos da população situadas na faixa de extrema pobreza de 4,6\% e 16,5\% para aqueles que estão na faixa de pobreza (CEPAL, 2016).

Vê-se, com isso, que o desenvolvimento do capital humano brasileiro não guarda relação direta com o grau de crescimento econômico que o país apresenta. O Brasil é a 9a (nona) maior economia mundial em termos de PIB per capita. Diante dessa situação, percebe-se que não se pode apenas olhar para um lado da moeda. Crescimento econômico é importante, mas não mais do que desenvolvimento do capital humano. Ambos devem andar de mãos juntas. Deste modo, ter o Estado regulador que desenvolva políticas públicas que vise a ajudar o mercado é essencial para o seu desenvolvimento sadio.

É preciso planejar para se fechar a conta Estado Social/Mercado. Em suma, para que o Welfare State consiga ser plenamente efetivado é necessário que economia seja incentivada. Acredita-se que a empresa é sim capaz de auxiliar o Estado no desenvolvimento do capital humano, na medida em que consegue realizar suas atividades. Para tanto, incentivar, distribuir, ampliar e auxiliar são mecanismos que devem ser usados pelo governo. Só com crescimento econômico se conseguirá pensar em políticas sociais pelo Estado.

\section{NOTAS}

1 Segundo o ranking de desenvolvimento do capital humano do Banco Mundial o Brasil está na octogésima primeira (81ํ) colocação de cento e noventa e cinco países (195) analisados. Disponível em: <http://www.br.undp.org/>. Acesso em 25 setembro 2018.

2 Segundo dados do Fórum Econômico Mundial. Disponível em: <https://www.weforum.org/ agenda/2018/04/the-worlds-biggest-economies-in-2018 >. Acesso em 25 setembro 2018.

3 Nesta circunstância, note que o Estado foi tratado de forma exógena, com sua ação, quando necessitada, servindo apenas para solucionar deficiências de mercado, intermediando interesses privados (ANTUNES, 2014, p. 14).

4 O liberalismo surgiu como ponto de partida na apreciação da autonomia privada. Sustenta-se nos princípios da liberdade, igualdade e fraternidade, cujo marco inicial se deu com a vitória da burguesia sobre o absolutismo. Assenta-se no absenteísmo estatal, na valorização da propriedade privada, no individualismo e na proteção ao indivíduo.

5 Inicialmente as grandes navegações e o desenvolvimento da burguesia se apoiaram na liberdade individual, na segurança das contratações e no respeito à autonomia privada.

6 Para os economistas clássicos, era através do liberalismo que se removeriam as barreiras que impediam o pleno desenvolvimento da riqueza. 
7 Smith (1996) alertava para o fato de que a presença do Estado era desnecessária, com sua ação sendo utilizada apenas para promover privilégios. A sociedade era capaz de organizar sua vida econômica de modo mais eficiente defendendo seus próprios interesses, livres de interferências de poderes contrários aos interesses dos indivíduos

8 França (2011, p. 93) afirma que o liberalismo reinou todo o século XVIII e vivenciou duas fases: a da conquista da liberdade e a da exploração da liberdade.

9 Nesse sentido ver o que escreve Judith Martins-Costa em Crise e modificação da noção de contrato no direito brasileiro.

10 Não se pode confundir Estado Social com Estado Socialista, pois aquele não rompe com o sistema capitalista. Estado Social, assim, é aquele que busca a efetivação do laissez-faire, ou seja, surge da ineficiência do Estado liberal em lidar com a "questão social". Segundo Bonavides (1997, p. 186), o Estado Social "coloca na sociedade todas as classes na mais estreita dependência de seu poderio econômico, político e social, em suma, estende sua influência a quase todos os domínios que dantes pertenciam, em grande parte, à área de iniciativa individual".

11 Em L'età dela decodificazione, Irti (1978) demonstra que o modelo de Estado pós Segunda Guerra Mundial - Estado Social - transformou a legislação europeia.

12 Fugia-se do Código Civil italiano (de 1942) em direção ao eixo principiológico e valorativo da sua Constituição (constitucionalização do Direito Civil), criava-se, com o movimento Civil-Constitucional, verdadeira "alergia" ao sistema codificado. Não mais se exigia da ordem jurídica sua completude, nem se admitia o sistema como exclusivamente lógico-dedutivo. 0 Código deveria, antes de mais nada, como sistema axiológico ou teleológico, "caracterizar os princípios gerais representantes dos valores mais importantes da ordem jurídica” (CANARIS, 1989, p. 66). Unificava-se os vários ordenamentos espaços, sob a ótica da parte geral do Código, que continuava a ser a base para a sistematização do Direito Privado. Assim, deveria haver confluência entre os sistemas internos (código) e externos (comunicação e aprendizagem do jurídico). 0 Direito pode ser pensado, aplicado e interpretado como ordem de referência apenas relativa, sensível a interpretação de fatos e valores externos. Devia-se permitir permanente discussão de problemas concretos cuja resolução não se mostrava adequado no pensamento problemático, onde a base do raciocínio se concentra na compreensão axiológica ou teleológica dos princípios gerais do Direito (MARTINS-COSTA, 1988, p. 47).

13 Neste período, os intitulados "direitos humanos" ressurgem na ordem do dia e tanto ficam efervescentes que veio à tona o projeto de uma tutela internacional cujo propósito se manifestara na Carta das Nações Unidas, de 1945, posteriormente materializada na Declaração Universal dos Direitos do Homem, de 10 de dezembro de 1948 (SILVA, 2011, p. 19).

14 Keynes (1982, p. 287-288), no livro da Teoria Geral do Emprego, do Juro e da Moeda, afirmava que: “O Estado deverá exercer uma influência orientadora sobre a propensão a consumir, em parte através de seu sistema de tributação, em parte por meio da fixação da taxa de juros (...) Não é propriedade dos meios de produção que convém ao Estado assumir. Se o Estado for capaz de determinar o montante agregado dos recursos destinados a aumentar esses meios e a taxa básica de remuneração aos seus detentores, terá realizado o que lhe compete".

15 mas um mundo de injustiças flagrantes - designadamente, a liberdade contratual entre empresários e trabalhadores tivera como resultado uma exploração social" (VIEIRA DE ANDRADE, 2008, p. 57)

16 No mesmo sentido Barcelona (1996, p. 89) afirma que o desenvolvimento da modernidade e das suas crises se apresentou como a "imagem de um grande e colossal processo de debilitação do Eu".

17 Isso porque o centro da tutela não é a propriedade, mas sim o sujeito em si.

18 Para Prata (1982, p. 7) a análise do conceito de autonomia privada e sua história revelam a inequívoca ligação deste conceito com os de sujeito jurídico e de propriedade. Já Meireles (2009) a atribuição da capacidade negocial ao indivíduo foi indispensável para promover a circulação dos bens. 0 sujeito moderno é o sujeito-proprietário. Entretanto, como a qualidade de proprietário não pertence a todos, o estatuto jurídico proprietário para a defesa e circulação dos bens, inter vivos ou mortis causa, traduz-se em mais um mecanismo de exclusão porque direcionado a uma classe de pessoas: a dos proprietários. 
19 Essa é a noção de regulação economica que se desenvolve nesse trabalho. Cumpre lembrar, entretanto, que o Estado também tem a função de regulação social que cuida da regulação para o bem-estar.

20 Fenômeno que Vogel (1996) descreve como "Freer Markets; More Rules".

21 Dentre os direitos sociais expressos no art. $6^{\circ}$ tem-se a educação, a saúde, a alimentação, o trabalho, a moradia, o transporte, o lazer, a segurança, a previdência social, a proteção à maternidade e à infância, a assistência aos desamparados. Salienta-se que desde a promulgação da Constituição Federal de 1988 o texto sofreu sucessivas alterações, via emenda constitucional para acrescentar outros direitos sociais, inflando o capítulo relativo a esta matéria. 0 supracitado art. $6^{\circ}$ incluiu direitos que inicialmente não estavam previstos. Neste sentido, a moradia, foi introduzida com a Emenda Constitucional n. ํ 26, de 14 de fevereiro de 2000 (BRASIL, 2000), empós, a alimentação, por meio da Emenda Constitucional n. 우 64, de 04 de fevereiro de 2010 (BRASIL, 2010), e os transporte, em face da Emenda Constitucional n.ํ 90, de 15 de setembro de 2015 (BRASIL, 2015).

22 Estes dispositivos constituem fundamentos e objetivos da República Federativa do Brasil.

23 Estes devem ser colmatados a alcançar, em sua trajetória, a função social da ordem econômica, nela incluída a efetivação de direitos sociais (POMPEU; AGUIAR, 2016, p. 183)

24 Cumpre lembrar que a ideia de capitalismo tardio foi desenvolvida, a princípio, por Natalia Moskovska, em 1943, e, no Brasil, observa-se tese homônima, de João Manuel Cardoso de Mello, que comenta a realidade após a abolição da escravatura no final do Século XIX e a industrialização com matriz na burguesia cafeeira (MELLO, 2009, p. 45-57).

25 Mendonça (2012, p. 151) escreve que "o desenvolvimento econômico dos Estados Unidos (EUA) se deu desde o período compreendido entre 1820 a 1865, desenvolvido a partir da Doutrina Monroe". Assim, os EUAs se lançaram na corrida industrial desde os anos de 1820, com as políticas expansionistas do Destino Manifesto e do "Big Stick".

26 A América Latina só conseguiu estruturar a expansão capitalista de suas economias quando estas se viram livres do jugo colonial, a saber na segunda década do século XIX (MENDONÇA; PIRES, 2012, p. 167).

27 No âmbito da América Latina, pode-se dizer que desde a década de 1970 Chile e Argentina já ensaiavam os primeiros passos rumo ao neoliberalismo. Note que estes países anteciparam o movimento que viria a acontecer por volta de 1980, com a chegada de Margareth Thatcher e Ronald Reagan ao poder no Reino Unido e nos Estados Unidos, respectivamente (IGLECIA; CARDOSO; STREICH, 2016, p. 9).

28 No mesmo sentido assevera Diniz e Boschi (2016, p. 25) para eles os países capitalistas de desenvolvimento clássico conseguiram se adaptar às variações que se estabeleceram no cenário pós-colonial. Enquanto que nos chamados países de desenvolvimento tardio, a tentativa de captar a complexidade do processo político subjacente à consolidação do capitalismo industrial não se furtou a certo viés.

29 A economia do país seguiu as linhas da colonização e se desenvolveu em torno de produtos primários (agrícola tropical). modelo de produção pautado no cultivo à terra não exigia nenhuma modernização na infraestrutura. Ademais os preços permaneciam sob a influência de baixos salários (FURTADO, 1970, p. 63). Em 1950 o país ainda era pobre e agrícola, apesar de vivenciar acelerado crescimento econômico desde o início do século. Sua renda per capita era baixa e seus indicadores sociais precários (VELOSO; FERREIRA, 2012, p. 1).

30 Veloso e Ferreira (2012, p. 3) afirmam que a renda per capita brasileira aumentou cinco vezes entre 1950 e 2011, de acordo com os dados das Contas Nacionais. No entanto, grande parte desse crescimento ocorreu entre 1950 e 1980, quando a renda per capita expandiu-se a uma taxa de $4,4 \%$ ao ano (a.a.) e praticamente quadruplicou no período. A partir de 1980, houve uma grande desaceleração do crescimento, e nos pouco mais de trinta anos seguintes a renda per capita cresceu apenas 0,9\% a.a.

31 Ostrom mostra-se ciente em relação aos limites da racionalidade, buscando defender a existência de teoria comportamental da ação individual a qual leve em consideração a atenção, a informação limitada, o processo cognitivo e o contexto (POTEETE; OSTROM; JANSSEN, 2011).

32 Ostrom ganhou o prêmio Nobel de Economia em 2009 ao demonstrar, por pesquisas de campo, desenvolvidas em comunidades ao redor do planeta. Ela descobriu que em muitos casos a tragé- 
dia dos comuns não se confirmava, por isso apontava a possibilidade de as comunidades locais desenharem instituições coletivas que possibilitassem o uso sustentável de recursos naturais comuns, como águas de rios, por exemplo.

33 Putnam chama esse patamar mínimo civilizatório de "comunidade cívica".

34 "As instituições de cunho cooperativo requerem aptidões e confiança interpessoais, mas essas aptidões e essa confiança são igualmente inculcadas e reforçadas pela colaboração organizada" (PUTNAM, 2002, p. 190).

35 Com 11 164.4, dados do CEPAL.

36 Disponível em: <http://hdr.undp.org/sites/default/files/2016_human_development_report.pdf $>$. Acesso em: 4 nov. 2018.

37 No anuário de 2017, a CEPAL apresentou estatísticas básicas da economia, da demografia social e da situação de desenvolvimento de região em específico período de tempo. 0 primeiro capítulo do anuário tratou de demografia e indicadores sociais, incluindo informações da população, trabalho, educação, saúde, moradia e serviços básicos. 0 segundo, versou sobre a estatística econômica, balança de valores e preços internos. No terceiro apresenta-se as informações estatísticas sobre o meio ambiente.

38 Por 100 mil habitantes. Entre os anos de 2015 a 2020.

39 Para o PwC em 2050 o Brasil deve ser a 5a maior economia do mundo em 2050. Segundo essa pesquisa, o PIB per capita projetado para o país deve ser de US\$7.540 em 2050, considerando dólares correntes, ante os US\$3.135 do ano passado.

40 O Doing Business "measures aspects of regulation that enable or prevent private sector businesses from starting, operating and expanding" (DOING BUSINESS, 2017, p. 01). Este demonstrou que "regulatory efficiency and regulatory quality go hand in hand. Economies that have efficient regulatory processes as measured by Doing Business also tend to have good regulatory quality" (DOING BUSINESS, 2017, p. 02 - 08). 0 referido relatório analisou 11 indicadores que, caso implantado, instigam a economia e atraem investimentos para o país. Entre eles: começar um negócio, conseguir alvarás de funcionamentos, existir eletricidade, regras pertinentes ao registro de propriedade, acesso ao crédito, proteção de investidores minoritários, pagamento de impostos, comércio externo, execução de contratos, processo de insolvência e regulação do mercado de trabalho. Estes indicadores são analisados com enfoque específico a cada ano, em 2017, a "14th edition, the Doing Business report demonstrates the power of a simple idea: measure and report the actual effect of a governmentpolicy".

41 Metas 1 e 8 correspondentemente. Disponível em: <https://nacoesunidas.org/pos2015/agenda2030/>. Acesso em: 13 nov. 2018.

42 Para Smith (1996) cabia ao Estado desempenhar o papel de garantidor de segurança e de estruturador da forma de governo.

43 O Capital de Marx (1867) também se baseou na ideia de que a ação do Estado é elemento pouco importante na determinação da dinâmica capitalista, diferentemente do período de acumulação primitiva, na qual o Estado, sob a liderança do monarca, tinha papel ativo, contribuindo para o aumento da produtividade e do desenvolvimento do comércio interno.

44 pelo menos numa primeira geração (ou dimensão) - enquanto esfera de intangibilidade do cidadão por parte do Estado.

450 entendimento de Constituição Dirigente tem fundamento em programa prospectivo de ação para a mudança social, no sentido de se conferir força jurídica para a mudança da sociedade.

46 Para Oliveira Júnior e Oliveira (2018, p. 39) "no âmbito interno, tem-se que a Constituição Federal pátria, promulgada em 1988, apresenta caráter notadamente dirigente, na medida em que traz em seu bojo de modo extensivo inúmeras promissões, demonstrando o cuidado empregado do legislador originário ao dispor sobre obrigações estatais e consubstanciando um projeto de construção do futuro".

47 Lembre-se que a realização desses direitos fundamentais é essencial para pleno desenvolvimento do sujeito.

48 "Não há como dissociar os serviços sociais universais, o objetivo de redistribuição e interação das rendas do objetivo maior do pleno emprego que norteou as políticas econômicas nacionais até os anos 80" (MISHRA, 1990, s. p.). Nesse contexto, a centralidade das instituições se justifica 
no fato de serem instrumentos primordiais de canalização dos mecanismos de mercado, "tanto para a realização de finalidades sociais quanto para a obtenção das condições estruturais necessárias à estabilidade macroeconômica e à sustentabilidade do processo de desenvolvimento das nações" (BRUNO, 2014, p. 12).

49 A obra simboliza importante marco para perspectiva econômica do Direito, vista sempre a partir de sua repercussão econômica (de custos).

50 Deve-se observar que os modelos welfarista ou solidarista são caracterizados por leis e códigos dotados de "conceitos jurídicos indeterminados" e de cláusulas gerais".

51 A presidente sofreu impeachment por não ter tido êxito em cumprir a meta estabelecida na LDO no ano de 2014 porque, basicamente, de 2012 até então, utilizava-se de política fiscal conhecida pelos economistas como "expansionista". Em uma linguagem comum, isso significa que não houve cuidado em conter as despesas, tampouco com o aumento da arrecadação. Por isso, desde o ano de 2011, o governo se utilizou de manobras contábeis para que não ficar registrado ou aparecer no balanço do Tesouro Nacional que o país foi incapaz de economizar. Ressalta-se que as estatais Petrobras e BNDES, e os bancos públicos foram utilizados como veículos para realizar as citadas manobras.

520 grau de investimento é uma nota atribuída pelas agências especializadas que garantem que um país é bom pagador aos seus credores, nota essa que pode ser capaz de atrair ou afastar investidores das dívidas públicas.

53 Quando a poupança interna brasileira é insuficiente para o pagamento de suas dívidas, recorre-se ao financiamento de investidores externos, a fim de que o país consiga realizar os investimentos necessários. Para tanto, o país emite títulos da dívida pública, que são empréstimos contratados no mercado internacional cujo retorno é atrelado a taxa de juros. Quanto maior for os juros brasileiros, maior será os rendimentos que o governo deverá pagar aos investidores. Por conta dos problemas fiscais do ano de 2014, o Brasil correu risco de perder grau de investimento das agências de classificação de risco, o que seria das mais graves consequências da manobra fiscal na Lei de Diretrizes Orçamentárias.

54 É a LDO quem estabelecerá as diretrizes de construção do orçamento fiscal de seguridade social e de investimentos dos três poderes: Executivo, Judiciário e Legislativo - e das empresas públicas e autarquias.

55 Projeção da diferença entre o que se vai arrecadar com o que se pretende gastar.

56 Nesse sentido, Velloso e Mendes (2004, p. 5) dispõem: "o primeiro é reconhecer o esgotamento e promover reformas nas instituições fiscais. Obviamente esse caminho tem o custo político de curto prazo, pois exige medidas que cortarão benefícios de segmentos organizados da população. Mas permitirá a aceleração do crescimento econômico e afastará o risco de crise. 0 caminho alternativo é tentar prosseguir com o modelo atual, evitando-se o custo político do ajuste. 0 melhor que se pode obter, nessa hipótese, é uma economia de baixo crescimento, incapaz de gerar renda suficiente para elevar o nível de desenvolvimento do país no longo prazo".

57 As agências devem regular com vistas a impedir arbitrariedades ou desrespeito às leis, nunca impedir o desenvolvimento econômico.

58 O Art. 165 §2º da CF/88 disciplina que "a lei de diretrizes orçamentárias compreenderá as metas e prioridades da administração pública federal, incluindo as despesas de capital para o exercício financeiro subsequente, orientará a elaboração da lei orçamentária anual, disporá sobre as alterações na legislação tributária e estabelecerá a política de aplicação das agências financeiras oficiais de fomento".

59 Diferente do orçamento privado, além de gastar menos do que se arrecada deve obter receitas não-financeiras (exemplo: tributos) e/ou cortar despesas não-financeiras, exemplo: pessoal (PASCOAL, 2006). Assim, adequado é quando se gasta menos do que se arrecada porque o excedente pode ser guardado em poupança ou utilizado para o consumo.

60 Regulação social é realizada por instituições majoritárias que balizam politicamente conflitos de interesse, ao passo que regulação economica é feita por instituições não majoritárias providas por quadros técnicos que buscam soluções otimizadas e eficientes. No presente artigo estar-se tratando da regulação economica.

61 Haber (2010) se refere como "regulação para o bem-estar" ou "regimes de bem-estar regulatório". 


\section{REFERÊNCIAS}

ALVES, José Eustáquio Diniz; BRUNO, Miguel A. P. População e crescimento econômico de longo prazo no Brasil: como aproveitar a janela de oportunidade demográfica? Disponível em: <http://www.abep.nepo.unicamp. br/encontro2006/docspdf/ABEP2006_302.pdf>. Acesso em: 15 out. 2018.

ANTUNES, Felipe da Silva. A importância do papel do estado na atividade econômica. A Economia em Revista, v. 22, n. 1, julho de 2014. Disponível em: <http://periodicos.uem.br/ojs/index.php/EconRev/article/viewFile/21272/ pdf_3>. Acesso em 17 out. 2018.

AQUINO, Crhistian Martins de; BUSSINGUER, Elda Coelho de Azevedo; BELIZÁRIO, Bethânia Silva. Soberania estatal absoluta em Hobbes: ponto de partida para um estudo racionalista dos direitos fundamentais. Revista de Direitos e Garantias Fundamentais, Vitória, n. 4, p. 65-82, jul./dez. 2008.

BOSCHI, Renato; DINIZ, Eli. Estado e sociedade no Brasil: uma revisão crítica In: SZWAKO, José; MOURA, Rafael; D’AVILA, Paulo Filho (Org.). Estado e sociedade no Brasil: a obra de Renato Boschi e Eli Diniz. Rio de Janeiro: CNPq, FAPERJ, INCT/PPED, Ideia D, 2016. p. 25 - 46.

BRASIL. Constituição (1988). Constituição da República Federativa do Brasil (de 05 de outubro de 1988). Assembleia Nacional Constituinte. Diário Oficial da República Federativa do Brasil, Brasília, DF, 05 out. 1988, Seção I, p. 1-32. Disponível em: http://www.planalto.gov.br/ccivil_03/constituicao/constituicao. htm. Acesso em: 4 out. 2018.

Emenda Constitucional n.o 26, de 14 de fevereiro de 2000 . Altera a redação do art. 6o da Constituição Federal. Congresso Nacional. Diário Oficial da União, Brasília, DF, 15 fev. 2000, Seção 1, p. 1. Disponível em: <http:// www.planalto.gov.br/ccivil_03/constituicao/Emendas/Emc/emc26.htm\#1>. Acesso em: 4 out. 2018.

. Emenda Constitucional n.o 64, de 04 de fevereiro de 2010. Altera a redação do art. 6엄 da Constituição Federal, para introduzir a alimentação como direito social. Congresso Nacional. Diário Oficial da União, Brasília, DF, 05 fev. 2010, Seção 1, p. 1. Disponível em: <http://www.planalto.gov.br/ccivil_03/ constituicao/Emendas/Emc/emc64.htm\#art1>. Acesso em: 4 out. 2018. 
Emenda Constitucional n.o 90, de 15 de setembro de 2015. Dá nova redação ao art. 60 da Constituição Federal, para introduzir o transporte como direito social. Congresso Nacional. Diário Oficial da União, Brasília, DF, 16 set. 2015, Seção 1, p. 1. Disponível em: <http://www.planalto.gov.br/ccivil_03/ constituicao/Emendas/Emc/emc90.htm>. Acesso em: 4 out. 2018.

BARCELONA, Pietro. El individualismo proprietário. Madrid: Trota, 1996.

BONAVIDES, Paulo. Curso de Direito Constitucional. 7. ed. São Paulo: Malheiros, 1997.

BRUNO, Miguel. Desafios do desenvolvimento socioeconômico brasileiro: uma perspectiva institucionalista do período recente. In: DANE, Felix (Ed.). 0 panorama socioeconômico do Brasil e suas relações com a Economia Social de Mercado. - Rio de Janeiro: Fundação Konrad Adenauer, 2014. p. 11 - 49.

CANARIS, Claus Wilhelm. Pensamento sistemático e conceito de sistema na ciência do direito. Tradução de Menezes Cordeiro. Lisboa: Fundação Calouste Gulbenkian, 1989.

CANOTILHO, José Joaquim Gomes. Constituição dirigente e vinculação do legislador: contributo para a compreensão das normas constitucionais programáticas. 2. ed. Coimbra: Coimbra Editora, 2001.

CAVALCANTE, Denise Lucena; CABRAL, Denise Maciel de Albuquerque. Os custos das políticas públicas: um olhar para o orçamento com foco no gasto. Revista de Direito Internacional Tributário, Brasília, v. 9, n. 1, p. 1-18, jan./ jun., 2014. Disponível em: <https://portalrevistas.ucb.br/index.php/RDIET/ article/view/5132>. Acesso em: 06 out. 2018.

COMISSÃO ECONÔMICA PARA A AMÉRICA LATINA E O CARIBE - CEPAL. Anuario Estadístico de América Latina y el Caribe 2016. División de Estadísticas febrero 2017. 9789211219395. LC/PUB.2017/2-P. 134 p.; grafs., tabls. Disponível em: <http://www.cepal.org/es/publicaciones/40972-anuario-estadisticoamerica-latina-caribe-2016-statistical-yearbook-latin>. Acesso em: 30 out. 2018.

FRANÇA, Beatriz. A (des) construção do direito privado em face da despatrimonialização do sujeito de direito civil constitucional: aspectos 
constitucionais da autonomia privada. In: NALIN, Paulo (Coord.). Contrato \& Sociedade. Curitiba: Juruá, 2011. v. II: A autonomia privada na legalidade constitucional.

FREIBERG, Arie. The tools of regulation. Australia: Federation Press, 2010.

FURTADO, Celso. Formação econômica da América Latina. Rio de Janeiro: Lia Editora, 1970.

FORUM ECONOMICO MUNDIAL. The world's biggest economies in 2018. Disponível em: <https://www.weforum.org/agenda/2018/04/the-worldsbiggest-economies-in-2018>. Acesso em: 10 nov. 2018.

GALDINO, Flávio. Introdução à teoria dos custos dos direitos: direitos não nascem em árvores. Rio de Janeiro: Lumen Juris, 2005.

GOLDENSTEIN, Lidia. Repensando a dependência. Campinas: UNICAMP. 21 de junho de 1994. 135 p. Tese. Universidade Estadual de Campinas. Instituto de Economia. 1994. Disponível em: http://www.bibliotecadigital.unicamp.br/ document/?code=vtls000076927. Acesso em: 01 out. 2018.

HABER, Hanan. Regulating-for-welfare: a comparative study of "regulatory welfare regimes" in the Israeli, British, and Swedish Electricity Sectors. Law \& Policy, Colorado: University of Denver, v. 33, n. 1, pp. 116-148, 2010. Disponível em: <https://onlinelibrary.wiley.com/doi/abs/10.1111/j.1467-9930.2010.00332. x>. Acesso em: 10 nov. 2018.

HUSPEL, Francisco. Autonomia privada na dimensão civil-constitucional: o negócio jurídico, a pessoa concreta e suas escolhas existenciais. Salvador: JusPODIVM, 2016.

IGLECIAS, Wagner; CARDOSO, Eliel; STREICH, Ricardo. Estratégias do desenvolvimento em questão: 0 debate sobre o papel do Estado no Brasil, México e República Bolivariana da Venezuela, 1989-2010. Santiago: Nações Unidas, CEPAL, Coleção Documentos de Projeto, março 2014. Disponível em: <http://repositorio.cepal.org/bitstream/handle/11362/36673/S2014189_ pt.pdf?sequence=1>. Acesso em: 25 out. 2018.

IRTI, Natalino. L'età dela decodificazione. Diritto Società, n. 03-4, 1978. 
KEYNES, J. M. A teoria geral do emprego, do juro e da moeda. São Paulo: Atlas, 1982.

LEVI-FAUR, David. The global diffusion of regulatory capitalism. Annals of the American Academy of Political and Social Sciences. n. 12. p. 598, 2005.

MAJONE, Giandomenico. From the positive state to the regulatory state: causes and consequences of changes in modes of governance. Journal of Public Policy, v. 17, n. 2, may/ aug., p. $139-167,1997$.

MARX, K. O Capital. Coleção os economistas. São Paulo: Nova Cultural, 1988.

MARTINS-COSTA, Judith. As cláusulas gerais como fatores de mobilidade do sistema jurídico. RT 680/47; que reenvia à FRADERA, Vera Maria Jacob de. 0 direito privado como uma geschossenheit: o direito privado como sistema aberto. Porto Alegre: [s.n.], 1988.

MASTRODI, Josué; RODRIGUES, Mônica. A vinculação do administrador às leis orçamentárias como meio de concretizar o direito fundamental à moradia: estudo sobre controle de políticas públicas de moradia no Município de Campinas. In: Revista Direitos Fundamentais e Democracia. Curitiba, v. 19, no. 19, jan./jun. 2016, pp. 03-21. Disponível em: http://revistaeletronicardfd.unibrasil.com.br/ index.php/rdfd/article/view/650/452. Acesso em: 01 jun. 2017.

McGINNIS, Michael D. An Introduction to IAD and the Language of the Ostrom Workshop: a simple guide to a complex framework. Policy Studies Journal, v. 39, n.1, p.169-183, 2011.

MEIRELLES, Rose Melo Vencelau. Autonomia privada e dignidade humana. Rio de Janeiro: Renovar, 2009.

MELLO, João Manuel Cardoso de. 0 capitalismo tardio. 11. ed. São Paulo: Unesp, 2009.

MENDES, Gilmar; BRANCO, Paulo Gustavo Gonet. Curso de direito constitucional. 7. ed. São Paulo: Saraiva, 2012.

MENDONÇA, Marina Gusmão de. 0 imperialismo norte-americano: do destino manifesto à doutrina do "Big Stick". In: MENDONÇA, Marina Gusmão de; PIRES, 
Marcos Cordeiro (Org.). Formação Econômica da América Latina. São Paulo: LCTE Editora, 2012, p. 151 - 166.

MENDONÇA, Marina Gusmão de; PIRES, Marcos Cordeiro. A divisão internacional do trabalho e o modelo primário-exportador. In: MENDONÇA, Marina Gusmão de; PIRES, Marcos Cordeiro (Org.). Formação Econômica da América Latina. São Paulo: LCTE Editora, p. 167 - 186, 2012.

MINOGUE, Martin. Governance-based analysis of regulation. Annals of Public Cooperative Economics. n. 73, p. 649-666, 2002.

MISHRA, R. The Welfare State in Capitalist Society: policies of rentrenchment and maintenance. Europe, North America and Australia, Studies in International Social Policy and Welfare, Harvester/Wheatsheaf: London,1990.

OLIVEIRA JÚNIOR, Vicente de Paulo A. de; OLIVEIRA, Fernanda Matos F. De. A (in)eficiência estatal na implementação de políticas públicas e do asseguramento de direitos abstratamente garantidos na constituição: crise da constituição dirigente? Revista de Direitos Fundamentais \& Democracia, Curitiba, v. 23, n. 1, p. 38-67, jan./abr., de 2018.

ORGANIZAÇÃO DAS NAÇÕES UNIDAS. Transformando nosso mundo: a agenda 2030 para o desenvolvimento sustentável. Disponível em: <https:// nacoesunidas.org/pos2015/agenda2030/>. Acesso em: 10 nov. 2018.

OSTROM, Elionor. Background on the Institutional Analysis and Development Framework. Policy Studies Journal. Oxford, v. 39, n. 1, 2011.

. Governing the Commons: the evolution of institutions for collective action. UK, Cambridge University Press, 2003.

PASCOAL, Valdecir. Direito financeiro e controle externo. 5 ed, Rio de Janeiro: Campus, 2006.

POTEETE, Amy; OSTROM, Elinor; JANSSEN, Marco. Working Together: collective action, the commons, and multiple methods in practice. Princenton University Press, 2011. 
PROGRAMA DAS NAÇÕES UNIDAS PARA O DESENVOLVIMENTO (PNUD). The Human Development Report 2018: human development for everyone. Disponível em: <http://hdr.undp.org/sites/default/files/2018_human_ development_report.pdf>. Acesso em 30 out. 2018.

POMPEU, Gina Vidal Marcilio; AGUIAR, Simone Coelho. A atuação dos Estados Latino-americanos na efetivação de direitos sociais: comparativo Brasil e Venezuela. Direito \& Paz. São Paulo, SP - Lorena, ano XVIII, n. 35, p. 175 - 193, 2. semestre, 2016. Disponível em: <http://revista.unisal.br/lo/index.php/ direitoepaz/article/view/443/273>. Acesso em: 28 out. 2018.

POMPEU, Gina Vidal Marcílio; MAGALHÃES, Átila de Alencar Araripe. Instituto da Falência transnacional como instrumento garantidor de segurança jurídica de credores. Revista de Direito Empresarial - RDEmp, Belo Horizonte, ano 13, n.2, p. 113 - 129, maio/ago.2016.

PRATA, Ana. A tutela constitucional da autonomia privada. Coimbra: Almedina, 1982.

PROGRAMA DAS NAÇÕES UNIDAS PARA O DESENVOLVIMENTO (PNUD). The Human Development Report 2016: human development for everyone. Disponível em: <http://hdr.undp.org/sites/default/files/2016_human development_report.pdf>. Acesso em 30 out. 2018.

PUTNAM, Robert D. Comunidade e democracia: a experiência da Itália moderna. Tradução de Luiz Alberto Monjardim. 3. ed. Rio de Janeiro: FGV, 2002.

Price water house Coopers $(\mathrm{PwC})$. The Long View How will the global economic order change by 2050? Disponível em: <https://www.pwc.com/ gx/en/world-2050/assets/pwc-the-world-in-2050-full-report-feb-2017.pdf>. Acesso em: 10 nov. 2018.

ROSA, Alexandre Morais da; MARCELLINO, Julio Cesar Jr. Os direitos fundamentais na perspectiva de custos e o seu rebaixamento à categoria de direitos patrimoniais: uma leitura crítica. Constituição, Economia e Desenvolvimento: Revista da Academia Brasileira de Direito Constitucional. Curitiba, v. 1, n. 1, ago./dez. p. 7-23, 2009. 
SANTOS, Wanderley G. Cidadania e Justiça. Rio de Janeiro, Editora Campus, 1979.

SILVA, Suzana Tavares da. Direitos fundamentais da arena global. Coimbra: Imprensa da Universidade de Coimbra, 2011.

SMITH, Adam. A riqueza das nações: investigação sobre sua natureza e suas causas. Trad. Luiz João Baraúna. São Paulo: Nova Cultural, 1996. Vol. I e II.

SUNSTEIN, Cass; HOLMES, Stephen. The cost of rights: why liberty depends on taxes. Nova Iorque: w.w. Norton \& Company, 1999.

VELOSO, Fernando; FERREIRA, Pedro Cavalcanti. O Desenvolvimento Econômico Brasileiro no Pós-Guerra. In: Veloso, F.; Ferreira, F.; Giambiagi, F.; Pessôa, S.. (Org.). Desenvolvimento Econômico: Uma Perspectiva Brasileira. Elsevier-Campus, 2012. Disponível em: <http://bibliotecadigital.fgv.br/dspace/bitstream/ handle/10438/14054/0_Desenvolvimento_Econ\%C3\%B4mico_Brasileiro_ no_P\%C3\%B3s_Guerra.pdf?sequence=1>. Acesso em: 15 out. 2018.

VELLOSO, Raul; MENDES, Marcos. Política fiscal insustentável e contabilidade criativa: quebrar o termômetro não diminui a febre, 2014. Disponível em: <http://www.raulvelloso.com.br/politica-fiscalinsustentavel-e-contabilidadecriativa/>. Acesso em: 10 nov. 2018

VIEIRA DE ANDRADE, José Carlos. Os direitos fundamentais na Constituição Portuguesa de 1976. 4 ed. Coimbra: Almedina, 2008.

VOGEL, Steven Kent. Freer markets, more rules: regulatory reform in advanced industrial countries. New York: Cornell University Press, 1996.

WINDHOLZ, Eric; HODGE, Graeme A. Conceituando regulação social e econômica: implicações para agentes reguladores e para atividade regulatória atual. Revista de Direito Administrativo, Rio de Janeiro, v. 264, p. 13-56, set/dez. 2013

WORLD BANK. 2018. Doing Business 2018: Equal Opportunity for All. Washington, DC: World Bank. DOI: 10.1596/978-1-4648-0948-4. License: Creative Commons Attribution CC BY 3.0 IGO. Disponível em: <http://www. doingbusiness.org/ /media/WBG/DoingBusiness/Documents/AnnualReports/English/DB18-Full-Report.pdf>. Acesso em: 30 out. 2018. 
Doing Business 2017: Equal Opportunity for All. Washington, DC: World Bank. DOI: 10.1596/978-1-4648-0948-4. License: Creative Commons Attribution CC BY 3.0 IGO. Disponível em: <http://www.doingbusiness.org/ / media/WBG/DoingBusiness/Documents/Annual-Reports/English/DB17-FullReport.pdf>. Acesso em: 30 out. 2018.

Recebido em: 30-11-2018

Aprovado em: 26-10-2020

\section{Gina Vidal Marcílio Pompeu}

Estágio Pós-Doutoral em Direito pela Universidade de Lisboa, Portugal (2017). Doutorado em Direito pela Universidade Federal de Pernambuco (2004). Mestrado em Direito (Direito e Desenvolvimento) pela Universidade Federal do Ceará (1994). Graduação em Direito pela Universidade Federal do Ceará (1987). Advogada inscrita na OAB-CE sob o n. 6101. Coordenadora e Professora do Programa de Pós-Graduação em Direito Constitucional da Universidade de Fortaleza, Mestrado e Doutorado (MINTER / DINTER) UNIFOR - CIESA. Analista Legislativo Advogada NSP 23 da Assembléia Legislativa do Estado do Ceará. E-mail: ginapompeu@unifor.br

\section{Liliane Gonçalves Matos}

Doutoranda em Direito Constitucional com ênfase nas Relações Privadas pela Universidade de Fortaleza - UNIFOR. Mestre em Direito Constitucional pela Universidade de Fortaleza - UNIFOR. Especialista em Direito e Processo Empresarial pela Universidade de Fortaleza - UNIFOR. Especialista em Direito e Processo Tributário pela Universidade de Fortaleza - UNIFOR. Professora. Advogada. Bolsista da FUNCAP/CAPES. E-mail: liliane.mat@hotmail.com

Universidade de Fortaleza, Coordenação do Programa de Pós-Graduação em Direito Constitucional.

Av. Washington Soares, 1321 bloco E sala 01

Edson Queiroz, Fortaleza - CE, 60811341 